\title{
Educação física no ensino médio: desenvolvimento de conceitos e da aptidão física relacionados à saúde
}

CDD. 20.ed. 796.017

\begin{tabular}{|c|c|}
\hline $\begin{array}{l}\text { Marcel Anghinoni CARDOSO* } \\
\text { Flávio Medeiros PEREIRA* } \\
\text { Mariângela da Rosa AFONSO* } \\
\text { Ivon Chagas da ROCHA JUNIOR }\end{array}$ & $\begin{array}{l}\text { *Escola Superior de } \\
\text { Educacãão Fisica, Uni- } \\
\text { versidade Federal de } \\
\text { Pelotas. } \\
\text { **Centro de Educação } \\
\text { Física e Desportos, } \\
\text { Universidade Federal } \\
\text { de Santa Maria. }\end{array}$ \\
\hline
\end{tabular}

\section{Resumo}

0 objetivo desse estudo foi verificar o desenvolvimento de conceitos, níveis de aptidão física relacionados à saúde, e padrão de atividade física proporcionado pelas aulas de Educação Física (EF). Compuseram a amostra 40 alunos (24 meninos, 16 meninas) do ensino médio. A aptidão física (APF) foi avaliada mediante os testes sentar e alcançar, corrida de nove minutos e resistência abdominal em um minuto, pertencentes à bateria de testes da PROESP. Os conceitos foram analisados por prova teórica com questões objetivas. 0 escore de atividade física (ATF) foi estimado pela versão longa do International Physical Activity Questionaire (IPAQ). Em 30 aulas de EF os conteúdos de ensino se relacionaram aos conceitos sobre alongamento e exercícios gímnicos: ginástica intervalada e corridas. Encontraram-se mudanças significativas na resistência abdominal, flexibilidade e conhecimento para ambos os sexos e na resistência aeróbia para meninas, indicando que as aulas, trabalhadas mediante procedimentos de ensino visando à promoção da saúde podem modificar os conceitos e a aptidão física relacionados à saúde de alunos do Ensino Médio.

Palavras-chave: Educação física; Conhecimento; Aptidão física; Ginástica intervalada; Ensino médio.

\section{Introdução}

A prática regular de exercícios físicos pode apresentar efeitos benéficos à saúde em diferentes populaçôes ${ }^{1-2}$, ainda que esse efeito possa ser contrário em uma parcela de indivíduos ${ }^{3}$. Sua prática pode ser um fator preventivo para diferentes patologias e, em diferentes faixas etárias, a prática de exercícios parece trazer consequências positivas do ponto de vista fisiológico, psicológico e social ${ }^{4-6}$.

Sob o prisma pedagógico, cada vez mais a Educação Física Escolar (EFE) é uma alternativa de intervenção em contrapartida aos preocupantes dados de crianças e adolescentes, com baixos níveis de aptidão física relacionada à saúde e estilo de vida sedentário. Hoenner et al. ${ }^{7}$ destacam que o único grupo de intervençôes com evidências conclusivas são as aulas de EF. SAlmon et al. ${ }^{8}$ indicam que as aulas de EFE são as mais indicados para a realização de programas interventivos.

Partindo dessa premissa, diferentes autores trazem abordagens que visam subsidiar o trato pedagógico da promoção da saúde na $\mathrm{EFE}^{9-12}$. A análise crítica das mesmas permite concluir que a promoção da saúde na EFE pode ser desenvolvida mediante procedimentos de ensino que se baseiem em três pontos básicos: contextualização teórica e prática acerca dos fatores biológicos, econômicos, políticos, sociais e culturais atinentes ao exercício físico; conteúdos de ensino que vão além dos tradicionais esportes de quadra; aulas que trabalhem com exercícios físicos em intensidade moderada e vigorosa.

As questôes levantadas pelos autores em questão também tiveram bastante influência na elaboração dos Parâmetros Curriculares Nacionais ( $\mathrm{PCN} s) \mathrm{da}$ EFE, tanto no Ensino Fundamental ${ }^{13}$ quanto na primeira versão do Ensino Médio ${ }^{14}$. Nesse sentido, é notável que a preocupação com a promoção da saúde na escola não seja apenas da comunidade científica, mas também de documentos que tem sua existência prevista em lei e que são de fácil acesso no meio escolar. 
Apesar disso, a pesquisas mostram que os pontos salientados como chave pelos autores colocados anteriormente náo têm sido destacados nas práticas pedagógicas da EFE. A EFE tem evidenciado que a prática de esportes de quadra em detrimento a outros conteúdos de ensino ${ }^{10,15-16}$ não tem impacto no conhecimento dos alunos em relação a aspectos ligados ao exercício físico ${ }^{17-18}$ e oferece poucos estímulos motores de intensidade moderada e vigorosa, que poderiam ocasionar modificaçôes a médio e longo prazo na aptidão física de crianças e adolescentes ${ }^{19-21}$.

Essa lacuna existente entre o que propóe a literatura e o que é feito na prática dá sustentação à elaboraçáo de propostas que visem trabalhar a promoção da saúde em aulas regulares de EF. Partese de procedimentos de ensino que proponham o desenvolvimento de conteúdos pouco abordados na realidade atual da $\mathrm{EF}$, de práticas pedagógicas que considerem a unicidade entre teoria e prática nos processos de ensino-aprendizagem e que ofereçam estímulos motores que possam modificar a aptidão física relacionada à saúde dos alunos. Além disso, objetiva-se ter impacto para a adoção de um estilo de vida ativo por parte dos mesmos.

Nesse sentido, conteúdos como a Ginástica, cuja essência é a exercitação motora e que trazem em seu cerne o trabalho com exercícios elementares, como apoios, abdominais, alongamentos, corridas, caminhadas, dentre outros, poderiam constituir-se como uma boa alternativa ao desenvolvimento de uma EF voltada à promoção da saúde. Ainda sobre a Ginástica, salienta-se que a mesma, ao longo dos anos, de acordo com Toledo ${ }^{22}$, perdeu espaço na escola, sendo muito mais vista em atividades extraescolares, como em academias, por exemplo. Em contrapartida, estudo de AzEvEDo Junior et al. ${ }^{23}$ indicou que a musculação e a ginástica de academia obtiveram um considerável aumento na preferência dos jovens nas últimas décadas.

Outro ponto importante a ser considerado é que a Ginástica, assim como o Esporte, as Lutas e a Dança é um dos conteúdos a serem desenvolvidos na EFE. Focando a promoção da saúde, a Ginástica possui um grande potencial didático-pedagógico, podendo contribuir para o ensino de diferentes questóes teóricas e práticas atinentes à exercitação motora. Dessa maneira, poderia ser possível que o aluno, subsidiado pela teoria e pela prática, aprenda a praticar e gostar da Ginástica, tornando-a parte de seu cotidiano.

Dessa forma, esse estudo teve como objetivo verificar o impacto de procedimentos de ensino centrados em atividades de ginásticas e subsidiados pelas bases teórico-pedagógicas que trazem como escopo principal a promoção da saúde na EFE sobre três variáveis: aptidão física relacionada à saúde, nível de atividade física e conhecimento sobre elementos sócio-políticos, biológicos e técnicas gestuais relacionadas à EF em escolares do EM.

\section{Método}

Este estudo teve caráter quase-experimental, composto por uma amostragem não-probabilística intenciona ${ }^{24}$. No entanto, houve apenas o acompanhamento de um grupo que recebeu a intervenção pedagógica, realizada pelo pesquisador em uma única escola. Com isso, vale ressaltar que não houve grupo controle, randomizaçáo da amostra, sujeitos e interventor cegos. Assim, o efeito encontrado náo pode ser delegado apenas a intervenção pedagógica, mas ao somatório desses fatores. Por outro lado, ainda assim entende-se como importante estudo desta natureza, pois o delineamento respeita a dinâmica comum das aulas dentro do contexto escolar e seus resultados auxiliam a elaboração de hipóteses sobre os aspectos investigados. Antes do início da coleta de dados, o projeto de pesquisa passou por avaliação no Comitê de Ética do Curso de Enfermagem da Universidade Federal de Pelotas, sendo aprovado sob o número de protocolo 018/2010. O Termo de Consentimento Livre e Esclarecido (TCLE) foi entregue a todos os alunos participantes do projeto para que levassem aos seus responsáveis, tendo em vista que eram menores de idade. A participação foi voluntária com liberdade de afastamento do projeto. Caso o mesmo não tivesse autorização de seus pais para a participação do projeto ou não tivesse interesse no mesmo, $\mathrm{o}$ aluno seguiria participando das aulas, mas seus dados não foram coletados. Os dados foram coletados no início e no fim do período de intervenção.

\section{Caracterização da amostra}

Compuseram a amostra deste estudo duas turmas de primeiro ano de EM, totalizando 40 alunos com média de idade de 14,5 $\pm 0,6$ anos. Foram excluídos da amostra aqueles alunos: a) impossibilitados de 
realizar todos os testes propostos; b) que não realizaram as duas fases de avaliação (pré e pós-teste); c) que não tiveram $75 \%$ de frequência nas aulas práticas; d) que não devolveram o TCLE assinado pelos pais. Os discentes que não fizeram parte da amostra final desta pesquisa não foram excluídos de nenhuma das atividades desenvolvidas durante 0 estudo, apenas não foram incluídos na amostragem.

A fim de caracterizar a amostra pertencente a este estudo, foram coletadas informações relativas ao sexo, nível socioeconômico, medido pelo Critério de Classificação Econômica do Brasil ${ }^{25}$, atividade física extraclasse, por meio da ficha de avaliação do PROESP-BR ${ }^{26}$ e índice de massa corporal, determinada por meio de medidas de peso e altura.

\section{Características da instituição de ensino e da disciplina de EF}

A escola onde foi realizado o estudo pertence à rede federal e ofertava o EM juntamente à educação profissional. Semanalmente existiam uma aula isolada de EF e outras duas sequenciais em dois encontros semanais, um encontro com 45 minutos e outro com 90 minutos. Cada aula tinha duração de 45 minutos. Para sua realização, a escola contava com uma sala de ginástica, uma quadra poliesportiva, dois campos de futebol ao ar livre e grande espaço disponível inerente a uma instituição voltada para a agroindústria. Quanto ao material, havia a contento, colchonetes, bolas, cones e outros que se adequaram ao desenvolvimento da pesquisa.

\section{Estrutura das aulas de EF}

Ao total o estudo compreendeu 30 aulas de EF com cada turma, incluindo testes e re-testes. $\mathrm{O}$ QUADRO 1 mostra a distribuição do período no que diz respeito aos pré-testes, intervenção e pós-testes, bem como a quantidade de alunos em cada aula.
QUADRO 1 - Distribuição do período de intervenção no que tange às avaliações iniciais e finais, período de intervenção e quantidade de alunos em cada aula.

\begin{tabular}{|c|c|c|c|}
\hline Semana & Aula & Atividade & $\begin{array}{l}\text { Quantidade } \\
\text { de alunos }\end{array}$ \\
\hline \multirow{3}{*}{1} & $04 / 05$ & Avaliaçōes iniciais & 40 \\
\hline & $05 / 05$ & Avaliaçōes iniciais & 40 \\
\hline & $05 / 05$ & Avaliaçōes iniciais & 40 \\
\hline \multirow{3}{*}{2} & $11 / 05$ & Avaliaçôes iniciais & 40 \\
\hline & $12 / 05$ & Intervençáo & 33 \\
\hline & $12 / 05$ & Intervençáo & 33 \\
\hline \multirow{3}{*}{3} & $18 / 05$ & Intervenção & 37 \\
\hline & $19 / 05$ & Intervençáo & 40 \\
\hline & $19 / 05$ & Intervençáo & 40 \\
\hline \multirow{3}{*}{4} & $25 / 05$ & Intervençáo & 32 \\
\hline & $26 / 05$ & Intervençáo & 35 \\
\hline & $26 / 05$ & Intervençáo & 35 \\
\hline \multirow{3}{*}{5} & $01 / 06$ & Intervençáo & 30 \\
\hline & $02 / 06$ & Intervençáo & 40 \\
\hline & $02 / 06$ & Intervençáo & 40 \\
\hline \multirow{3}{*}{6} & $08 / 06$ & Intervençáo & 30 \\
\hline & $09 / 06$ & Intervenção & 29 \\
\hline & $09 / 06$ & Intervençáo & 29 \\
\hline \multirow{3}{*}{7} & $15 / 06$ & Intervençáo & 36 \\
\hline & $16 / 06$ & Intervençáo & 33 \\
\hline & $16 / 06$ & Intervençáo & 33 \\
\hline \multirow{3}{*}{8} & $22 / 06$ & Intervençáo & 20 \\
\hline & $23 / 06$ & Feriado & Zero \\
\hline & $23 / 06$ & Feriado & Zero \\
\hline \multirow{3}{*}{9} & $29 / 06$ & Intervenção & 19 \\
\hline & $30 / 06$ & Conselho de Classe & Zero \\
\hline & $30 / 06$ & Conselho de Classe & Zero \\
\hline \multirow{3}{*}{10} & $06 / 07$ & Intervenção & 38 \\
\hline & 07/07 & Intervenção & 37 \\
\hline & 07/07 & Intervenção & 37 \\
\hline \multirow{3}{*}{11} & $13 / 07$ & Avaliaçōes finais & 40 \\
\hline & $14 / 07$ & Avaliaçōes finais & 40 \\
\hline & $14 / 07$ & Avaliaçōes finais & 40 \\
\hline 12 & $20 / 07$ & Avaliaçōes finais & 40 \\
\hline
\end{tabular}


A coleta de dados só pode ser iniciada em maio, com a justificativa da instituição de que era necessário o período de um mês para que os estudantes se ambientassem à escola. Assim, nesse primeiro mês, os alunos tiveram aulas de EF com o professor titular dessas turmas.

As aulas que foram desenvolvidas neste estudo tiveram como referencial teórico básico as propostas teóricas voltadas à promoção da saúde na $\mathrm{EF}^{9-12}$. Do ponto de vista prático, o conteúdo de ensino principal foi a Ginástica, trabalhada mediante a metodologia de Pereira ${ }^{27}$ denominada de Ginástica Intervalada (GI):

A GI compreende a prática de conjunto de exercícios físicos, com alternância na intensidade dos esforços, em açōes conscientes, processuais e objetivadas. A GI é uma forma ginástica onde, metodicamente, exercícios mais suaves, de caráter de espaçamento e de manutenção do corpo em atividade, se intercalam com outros exercícios ginásticos mais fortes e mais específicos (p.10).

Basicamente, a GI objetiva a prática de exercícios elementares, como apoios, polichinelos, abdominais, alongamentos, corridas estacionárias e com percurso, caminhadas, etc. Visa a melhoria de capacidades físicas como a flexibilidade (FLX), a resistência aeróbia (RA) e a resistência muscular localizada (RML) e requer que o praticante se concentre mentalmente no que está realizando.

Concomitantemente à GI foram desenvolvidas atividades esportivas, compreendidas de esportes coletivos de quadra, como futsal, basquetebol, voleibol e handebol. Foram livremente escolhidas e geridas pelos alunos, sendo também de participação facultativa. Essas atividades, dado seu caráter facultativo e de autogestão dos alunos, tendo como base o interesse dos mesmos em praticá-las, tinham como rotina o desenvolvimento nos 15 minutos finais da aula dupla, uma vez por semana e com intensidade baseada no envolvimento de cada aluno na prática esportiva. Essas características não foram controladas, dado seu pouco tempo de desenvolvimento e caráter recreativo destas atividades. Com isso, entende-se que a probabilidade de ter afetado o comportamento das características estudadas foram pequenas. Há ciência que a inserção destas atividades esportivas fragilizam os resultados deste estudo, à medida que podem ter efeito aditivo nos resultados da prática dos exercícios de ginástica.

O objetivo de ensino deste estudo foi de proporcionar estímulos motores e cognitivos, visando desenvolver os conceitos e a aptidão física relacionados à saúde.
Esses conteúdos foram trabalhados ao longo das aulas, utilizando subsídios advindos das próprias práticas motoras propostas e em atividades extras propostas pelo professor, como a leitura de textos complementares.

Os conteúdos desenvolvidos a cada aula foram contextualizados náo apenas sob o ponto de vista biológico (anatomia, nutrição, biomecânica), mas também considerando questôes culturais (modificações nos hábitos de vida da população ao longo dos anos), políticas (políticas públicas voltadas à manutenção de um estilo de vida ativo), e socioeconômicas (barreiras econômicas que impossibilitam populaçôes mais humildes de ter acesso a academias, bem como alternativas para essas camadas populacionais) que têm influência sobre a aquisição de um estilo de vida ativo.

Durante todo o desenvolvimento do estudo sempre o pesquisador esteve presente e trabalhou de forma aproximada dos alunos. Nas fases cognitivas e ginásticas apoia-se no que SCHULDHEISZ e VAN DER $\mathrm{MARS}^{28}$ consideram como "supervisão ativa", e que propicia ganhos efetivos na aprendizagem.Embasando em XIANG e LEE ${ }^{29}$ sobre a forte ligação entre o alcance dos objetivos e o ambiente motivacional, valorizava-se cada pequeno progresso evidenciado pelos alunos.

Quanto aos métodos de ensino, em todas as aulas durante a exercitação ginástica utilizou-se o método global $^{30}$. Desse modo, nenhum exercício físico foi fracionado. Polichinelos, abdominais, apoios e outros movimentos relacionados à GI eram ensinados sem uma divisão em partes, obedecendo à premissa para o método global. Quanto à quantidade de escolares interagindo na execução dos exercícios de GI, em todos os encontros, utilizou-se de técnicas de ensino: a) individualizadas, sem interação imediata entre os alunos; b) técnicas de ensino em duplas, com um auxiliando ou participando da exercitação do outro. Em quatro ocorrências houve exercitação ginástica em trios.

Quanto aos estilos de ensino, baseado no espectro de Mosston e AswhORTH ${ }^{30}$, utilizou-se, principalmente, de:

- tarefas (professor determinava as tarefas e os alunos executavam) em todas as 30 aulas;

- auto checagem (tarefas determinadas pelo professor com auto avaliação dos alunos) em 13 aulas;

- inclusão (todos alunos em tarefas propostas pelo professor, modificadas de acordo com a capacidade de cada um), em 22 aulas;

- descoberta guiada (o professor determina as tarefas, e por meio de perguntas aos alunos os conduz a descobrir e sanar seus erros), em cinco aulas;

- produção divergente (os alunos tomam decisões diversas para atingir os objetivos propostos) em quatro aulas. 
O desenvolvimento das atividades ginásticas não contou com a presença de implementos nem de acompanhamento musical. Mesmo enfatizando a região abdominal, membros inferiores e superiores, a exercitação ginástica buscava trabalhar todas as partes do corpo. O principal elemento motivacional externo utilizado pelo professor foi o conhecimento atrelado às práticas. Cada atividade proposta era sempre justificada, buscando fazer com que os alunos entendessem o processo em que estavam inseridos e a importância do mesmo para suas vidas. Esses aspectos permitiram uma situação adequada de envolvimento dos alunos nas atividades, mesmo naquelas em que houve maior necessidade de vigor físico.

Na prática esportiva de Futsal, Handebol e Basquetebol, sempre os alunos se organizaram em grandes grupos, em equipes. Também apoiado em Mosston e Aswhorth ${ }^{30}$ nessa parte esportiva, devido à imprevisibilidade das açôes e a autonomia dos alunos durante o jogo, o estilo de ensino predominante foi o iniciado pelo aluno (os alunos planejam todas as suas atividades).

Embasando-se em metodologia de ensino de conteúdos cognitivos proposta por Pereira ${ }^{31}$, os conteúdos foram trabalhados por meio de conversas nas partes iniciais e finais das aulas. Estas conversas partiam das situaçóes vivenciadas na parte prática das aulas de EF. Nas últimas semanas foram inseridos temas atinentes a questôes não biológicas relacionadas à prática de exercícios físicos. Eram feitos questionamentos, esclarecidas dúvidas e enfatizada a importância do conhecimento para subsidiar práticas motoras imediatas e futuras. Contudo, as aulas práticas não eram interrompidas para se trabalhar estes conceitos. Durante a parte prática eram feitos apontamentos pelo professor, retomados de forma mais aprofundada no final da aula. Em nenhum momento do estudo foi realizada alguma aula totalmente conceitual em sala de aula. $\mathrm{O}$ quadro abaixo mostra uma síntese da distribuição dos conteúdos teóricos durante o período de intervençáo.

QUADRO 2 - Distribuição dos conteúdos teóricos ao longo do período de intervenção, desconsiderando os períodos de avaliação, feriados e conselho de classe.

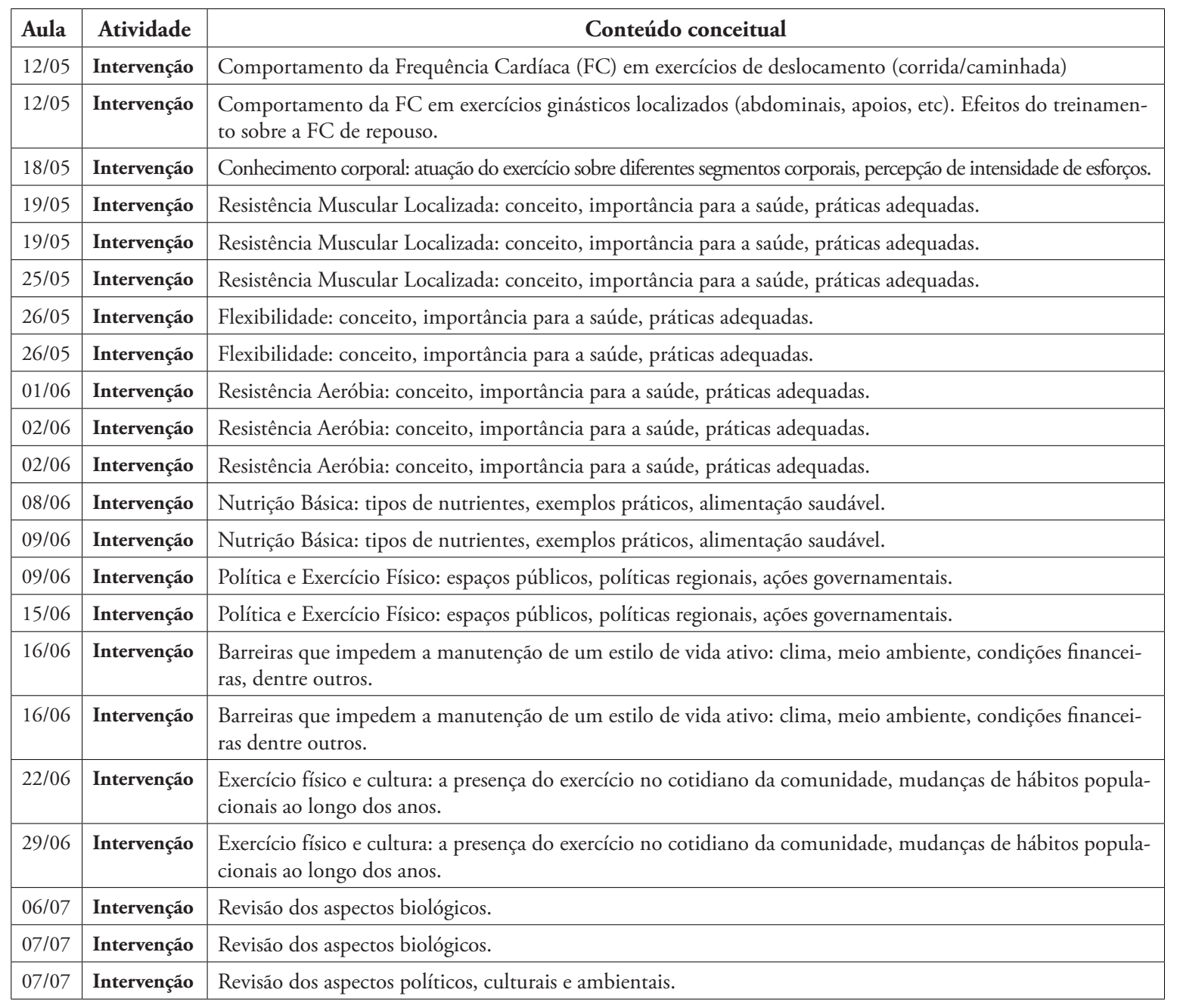


Havia uma alteração metodológica entre a aula isolada (quarta-feira) e a dupla (quinta-feira). Nas aulas isoladas eram desenvolvidos conteúdos somente com GI. Nas aulas duplas, devido ao maior tempo disponível, inicialmente eram trabalhados exercícios de alongamento e, posteriormente, atividades de corridas/caminhadas e GI. Nos 15 minutos finais do segundo período, a prática dos esportes escolhidos pelos alunos.

Para o desenvolvimento da flexibilidade, utilizouse nas semanas 2, 3, 4, e 5 exercícios de Alongamento Suave, que de acordo com Anderson ${ }^{32}$, consistem em estender a musculatura até o limite de uma pequena tensão, sustentando por 30 segundos. Nas semanas 6, 7, 8, 9, e 10 utilizou-se o Alongamento Progressivo, que consiste em um alongamento que imprima uma tensáo que vá além da impressa no método suave, sustentando também por 30 segundos $^{32}$. A flexibilidade era trabalhada sempre nos 15 minutos iniciais da aula de quartafeira e 20 minutos iniciais das aulas quinta-feira.

A resistência aeróbia foi trabalhada por meio de exercícios intervalados de corrida e caminhada, durante 10 minutos na quarta-feira e 20 minutos na quinta-feira, sendo que, ao longo do processo, foi sendo aumentado o tempo de corrida e diminuído o tempo de caminhada. Os alunos realizavam a mensuração manual da frequência cardíaca orientada pelo professor sempre nos períodos de caminhada, e eram instruídos a manterem-se entre 130 e 150 bpm durante a atividade.

A resistência muscular localizada foi trabalhada com circuitos de atividades para todos os segmentos corporais, com exercícios realizados com o peso do próprio corpo em períodos de 20 minutos nas quartas-feiras e de 30 minutos na quinta-feira. Nas semanas 1,2 e 3, os alunos eram instruídos, em cada exercício, a realizarem três séries de 15 repetições com intervalo entre séries de 30 segundos, sendo que, indicando a incapacidade de realizar tal esforço, podiam fazer menos. Nas semanas 4, 5, 6 e 7, as séries aumentaram para 20 repetições com intervalo entre séries de 30 segundos, podendo, a cargo de cada aluno, fazer mais repetiçôes respeitando o limite de três séries de 25 repetiçóes ou menos fazendo no mínimo 15. Nas últimas semanas, passaram a ser realizadas três séries de 20 ou 25 repetiçóes com intervalo entre séries de 30 segundos, podendo fazer menos caso relatada a incapacidade ou observada pelo professor.

\section{Avaliação do processo}

A aptidão física relacionada à saúde foi avaliada mediante a realização de três testes: sentar e alcançar (FLX), corrida de nove minutos (RA) e resistência abdominal (ABD), protocoladas pela bateria de testes da PROESP-BR ${ }^{26}$.

Apoiado em Pereira ${ }^{17}$ os conceitos foram avaliados mediante a realizaçáo de uma prova teórica, com oito questôes de múltipla escolha e uma questáo dissertativa, tendo como nota máxima 10 e nota mínima zero. $\mathrm{O}$ referido instrumento foi avaliado por professores universitários, sendo que características como conteúdo, linguagem, especificidade adaptados aos objetivos do estudo. O instrumento tinha como temas norteadores questôes biológicas (fisiologia, nutrição, anatomia), sócio-políticas (fatores influentes na manutenção de um estilo de vida ativo) e técnicas gestuais (execução correta de exercícios, biomecânica de exercícios ginásticos). Os temas condisseram com os conteúdos trabalhados durante o processo de ensino. Apresenta-se o detalhamento da prova no ANEXO 1.

O nível de atividade física foi medido pela versão longa do Questionário Internacional de Atividade Física (IPAQ). Foram consideradas para a análise apenas as seguintes seçóes: atividade física como meio de transporte; atividades físicas de recreação, esporte, exercício e de lazer.

\section{Análise estatística}

A análise estatística foi desenvolvida no pacote estatístico Stata versão 10.0. A simetria das variáveis foi averiguada mediante o teste formal de hipótese Shapiro Wilk, bem como a inspeção visual da curva normal. Por meio disso, constatou-se o comportamento assimétrico das variáveis deste estudo, optando-se por testes estatísticos não paramétricos para análise dos dados.

Os resultados iniciais e finais foram confrontados mediante a realizaçáo do Teste de Wilcoxon. Foram considerados significativos resultados com valor de $\mathrm{p}<0,05$. 


\section{Resultados}

A TABELA 1 mostra a distribuição entre meninos e meninas na amostra final ( 60 e $40 \%$, respectivamente). Quanto ao nível socioeconômico, a maior parte dos alunos se situa na classe B2 (50\%), seguida pela classe C1 (30\%), C2 (10\%), B1 (7,5\%) e A2 (2,5\%). No que diz respeito à atividade física extraclasse, $62,5 \%$ dos alunos relataram praticar alguma atividade extraclasse sem regularidade semanal (futebol com os amigos, ciclismo, etc), enquanto $37,5 \%$ relataram não realizar nenhuma atividade. Quanto ao IMC, 90\% dos alunos se encontravam em situação normal, com apenas três casos de sobrepeso e um de obesidade.

A TABELA 2 mostra mudanças significativas para a resistência abdominal e na avaliação teórica para alunos de ambos os sexos. No que diz respeito à flexibilidade, foram encontradas mudanças significativas. A resistência aeróbica modificou-se significantemente apenas para as alunas.
A mensuraçáo do escore de ATF dos alunos no deslocamento e no lazer, por meio do IPAQ, foi utilizada somente para verificar as possíveis modificaçóes no nível de atividade física ocorridas durante o estudo. Estatisticamente, não foram encontradas mudanças significativas, independente do sexo.

A TABELA 3 indica que os alunos que não praticavam nenhuma atividade extraclasse tiveram mudanças significativas na resistência abdominal e no conhecimento e significativas na flexibilidade e na resistência aeróbica. A resistência abdominal e o conhecimento tiveram mudanças significativas para os alunos que relataram praticar atividades extraclasse esporadicamente. A flexibilidade e a resistência aeróbia não se modificaram significativamente para este grupo. O escore de ATF não se modificou significativamente em nenhum dos dois grupos.

TABELA 1 - Caracterização da amostra quanto ao nível socioeconômico, prática de atividade extraclasse e índice de massa corporal (IMC), considerando uma amostra de 60\% de meninos e $40 \%$ de meninas.

\begin{tabular}{|c|c|c|c|}
\hline Variável & $\%$ & $\%$ & $\%$ \\
\hline & Meninos & Meninas & Total \\
\hline & 60 & 40 & 100 \\
\hline \multicolumn{4}{|l|}{ Nível socioeconômico } \\
\hline A2 & 2,5 & 0 & 2,5 \\
\hline B1 & 2,9 & 2,5 & 7,5 \\
\hline B2 & 19,9 & 20 & 50 \\
\hline $\mathrm{C} 1$ & 33,3 & 10 & 30 \\
\hline $\mathrm{C} 2$ & 2,5 & 7,5 & 10 \\
\hline \multicolumn{4}{|l|}{ Atividade extra classe } \\
\hline Sim & 22,5 & 15 & 37,5 \\
\hline Não & 37,5 & 25 & 62,5 \\
\hline \multicolumn{4}{|l|}{ IMC } \\
\hline Normal & 54 & 36 & 90 \\
\hline Sobrepeso & 2,5 & 5 & 7,5 \\
\hline Obesidade & 0 & 2,5 & 2,5 \\
\hline
\end{tabular}


TABELA 2 - Mediana, Intervalos Interquartis e significância estatística da Resistência Abdominal (ABD), Flexibilidade (FLX), Resistência Aeróbia (RA), Avaliação Teórica (COH) e Escore de Atividade Física (ATF) pré-teste e pós-teste de acordo com gênero.

*Teste de Wilcoxon

\begin{tabular}{llccccccc}
\hline Variáveis & \multicolumn{3}{c}{ Pré-teste } & & Pós-teste & & Valor $^{*}$ \\
\hline \multirow{3}{*}{ ABD (n' de rep.) } & Masculino & 24,5 & 30 & 36 & 34 & 41,5 & 47 & $<0,001$ \\
& Feminino & 19,5 & 24 & 30 & 27,5 & 33,5 & 45,5 & $<0,001$ \\
FLX (cm) & Masculino & 24 & 32,5 & 37 & 25,5 & 35 & 39,3 & 0,009 \\
& Feminino & 33,5 & 36 & 39,5 & 36,3 & 38,3 & 42,5 & 0,005 \\
RA (metros/9') & Masculino & 1408,5 & 1570 & 1701 & 1500 & 1607,5 & 1846 & 0,076 \\
& Feminino & 1118,5 & 1200 & 1320,5 & 1195 & 1292,5 & 1369 & 0,009 \\
COH. (nota) & Masculino & 2,5 & 3,6 & 5 & 5,4 & 6,9 & 7,3 & $<0,001$ \\
& Feminino & 2,8 & 3,8 & 3,9 & 5,1 & 6,6 & 8 & $<0,001$ \\
ATF (min. semana) & Masculino & 222,5 & 437,5 & 817,5 & 337,5 & 540 & 935 & 0,886 \\
& Feminino & 125 & 487,5 & 720 & 162,5 & 365 & 935 & 0,309 \\
\hline
\end{tabular}

TABELA 3 - Mediana, Intervalos Interquartis e significância estatística da Resistência Abdominal (ABD), Flexibilidade (FLX), Resistência Aeróbia (RA), Avaliação Teórica ( $\mathrm{COH})$ e Escore de Atividade Física (ATF) pré-teste e pós-teste de acordo a prática de atividade física extraclasse.

\begin{tabular}{|c|c|c|c|c|c|c|c|c|c|}
\hline \multirow[t]{2}{*}{ `Teste de Wilcoxon } & \multicolumn{2}{|l|}{ Variáveis } & \multicolumn{3}{|c|}{ Pré-teste } & \multicolumn{3}{|c|}{ Pós-teste } & \multirow[t]{2}{*}{ Valor $\mathbf{p}^{*}$} \\
\hline & \multirow{3}{*}{ ABD (no de rep.) } & & Q25\% & Q50\% & Q75\% & Q25\% & Q50\% & Q75\% & \\
\hline & & Sim & 24 & 30 & 41 & 32 & 42 & 48 & $<0,001$ \\
\hline & & Não & 20 & 25 & 31 & 28 & 37 & 45 & $<0,001$ \\
\hline & \multirow[t]{2}{*}{ FLX $(\mathrm{cm})$} & Sim & 24 & 36,5 & 41 & 26 & 36 & 42 & 0,028 \\
\hline & & Não & 32,5 & 35,2 & 36,7 & 34,5 & 36,5 & 41 & 0,005 \\
\hline & \multirow[t]{2}{*}{ RA (metros/9') } & Sim & 1540 & 1603 & 1802 & 1540 & 1800 & 1900 & 0,137 \\
\hline & & Não & 1172 & 1268 & 1370 & 1224 & 1322 & 1479 & 0,002 \\
\hline & \multirow[t]{2}{*}{ COH. (nota) } & Sim & 2,5 & 3 & 4,5 & 5,3 & 6,7 & 7,5 & $<0,001$ \\
\hline & & Não & 2,7 & 3,7 & 4,8 & 5,4 & 6,9 & 7,9 & $<0,001$ \\
\hline & \multirow[t]{2}{*}{ ATF (min. semana) } & Sim & 200 & 300 & 360 & 210 & 315 & 360 & 0,337 \\
\hline & & Não & 30 & 100 & 260 & 85 & 110 & 300 & 0,841 \\
\hline
\end{tabular}

\section{O cotidiano das aulas}

A duração das aulas de EF era de 45 minutos. Contudo, a cada aula isolada eram perdidos, em média, $15 \pm 1,3$ minutos, devido ao deslocamento dos alunos de suas salas de aula até o local da aula de EF, uniformização dos mesmos e controle da frequência, concordando com Pereira ${ }^{10}$ que, em análise do cotidiano das aulas de EF, encontrou uma realidade similar a esta. Dessa forma, o tempo de cada aula isolada se reduzia, em média, para 30 minutos. Quando aula era sequencial o tempo médio foi de $75 \pm 1,5$ minutos.
A falta de um intervalo entre os dias de aula também foi prejudicial à análise dos dados, à medida que a organizaçáo das aulas não respeita, conforme Powers e Howley ${ }^{33}$, a recuperação entre as sessões, um dos princípios básicos do treinamento desportivo. Dessa forma, analisando o trabalho realizado sob um prisma fisiológico, a organização do horário foi um fator limitante à coleta de dados, visto que as aulas eram realizadas na quarta-feira (aula isolada) e quinta-feira (aula dupla).

Outro problema constatado ao longo do processo foi a quebra de sequência nas aulas. Em dois momentos, em virtude de um feriado e de um conselho de classe, duas aulas sequenciais acabaram 
não acontecendo. Em decorrência disso, os alunos internos, que moravam na instituição, acabavam deixando a escola um dia antes do que habitualmente faziam para ficarem mais tempo em suas cidades de origem. Essa situação acabou prejudicando o estudo em duas semanas consecutivas, pois um feriado e um conselho de classe aconteceram na segunda e quarta semana do mês de junho, como visto no QUADRO 1.

\section{Discussão}

Os dados encontrados nessa pesquisa abrem precedentes para diversas discussóes. A possibilidade de a EFE ser um espaço para o aprimoramento da aptidão física relacionada à saúde, a viabilidade de aplicação de procedimentos de ensino que tenham como foco a promoção da saúde na EFE e a possibilidade de utilização de conteúdos diferentes dos esportes de quadra, nesse caso, a Ginástica, são os pontos primordiais que serão abordados na discussáo dos resultados desse estudo.

No que tange ao nível de aptidão física relacionada à saúde da amostra analisada, com base no Manual de Normas da PROESP-BR ${ }^{26}$, pode-se constatar que os meninos, na fase pré-teste, tinham níveis de flexibilidade e resistência aeróbia satisfatórios, e resistência abdominal abaixo para o esperado para a idade. Após a intervenção, flexibilidade e resistência aeróbia tiveram evolução e mantiveram-se em nível satisfatório, assim como a resistência abdominal, com a evolução conseguida atingiu os níveis esperados para a idade. Quanto às meninas, na fase pré-teste as mesmas tinham de resistência aeróbia e resistência abdominal abaixo do esperado para a idade, e flexibilidade condizente com o esperado. Após a intervenção, as meninas mantiveram níveis satisfatórios de flexibilidade e passaram também a ter um nível resistência abdominal e resistência aeróbia condizente com as idades, a partir da evolução conseguida ao longo do processo.

No que diz respeito ao aprimoramento da APF relacionada à saúde em aulas de EFE, os resultados indicam que, em três capacidades físicas analisadas, duas apresentaram modificaçôes significativas para ambos os sexos. Estudos realizados na realidade educacional brasileira, que traz uma carga horária cada vez mais reduzida para EF e que oferece condiçóes de trabalho muitas vezes questionáveis do ponto de vista financeiro e de condiçóes de efetivação das
O fato de a coleta de dados ter iniciado um mês após o início das aulas também foi outro fator a ser considerado. Nesse período foram desenvolvidas aulas predominantemente esportivas. Nesse contexto, a inserção de aulas centradas em atividades ginásticas demorou a ser aceita pelos alunos. Contudo, ao longo do processo essa situação foi se revertendo, estimulada pelos procedimentos de ensino desenvolvidos nesta pesquisa.

ações docentes, também encontraram resultados que se assemelham aos deste trabalho.

Milanezi ${ }^{34}$ em pesquisa realizada com 96 alunos do sexo masculino durante 34 semanas no Ensino Fundamental, constatou que alunos que frequentaram apenas aulas de EF apresentaram evolução significativa na resistência abdominal, resistência aeróbia e flexibilidade ao fim do processo. Salvo quanto à resistência aeróbia, os dados do estudo de Milanezi ${ }^{34}$ convergem com os achados dessa pesquisa quanto à aptidão física relacionada à saúde. Vale ressaltar que o tempo de desenvolvimento de cada estudo e o nível de ensino diferem entre o presente estudo e o realizado por Milanezi ${ }^{34}$.

Schonardie Filho ${ }^{35}$ em um estudo aplicado junto a 28 alunos do ensino médio durante o período de um ano letivo, encontrou mudanças significativas tanto na aptidão física relacionada à saúde (flexibilidade, resistência aeróbia e resistência abdominal) quanto a aquisição de conceitos acerca de fatores biológicos, biomecânicos, sócio-políticos e culturais relacionados ao exercício físico, medidos por intermédio de uma avaliação teórica.

Os achados de Schonardie Filho ${ }^{35}$ se assemelham aos desta pesquisa, sendo importante considerar que, assim como neste estudo, por intermédio das aulas de EFE, conseguiu-se indicar modificações significativas em questóes ligadas ao conhecimento dos alunos sobre conceitos ligados ao exercício físico.

Pereira $^{36}$ em pesquisa realizada também com o EM durante três bimestres letivos, mostra mudanças significativas na resistência abdominal, flexibilidade e nota de avaliação teórica após intervenção pedagógica focando o ensino da EF por intermédio de aulas direcionadas à prática da Ginástica, com ênfase na GI. O presente estudo, além de encontrar resultados semelhantes aos encontrados nessa pesquisa, 
faz alusão à Ginástica na condição de conteúdo de ensino para o aprimoramento da aptidão física relacionada à saúde e no conhecimento.

Dessa forma, tanto os estudos relacionados acima quanto os resultados conseguidos neste estudo apontam para a possibilidade de aprimoramento da aptidão física e do conhecimento por intermédio da EFE. No que diz respeito à resistência aeróbia, variável que não teve alteraçôes significativas neste estudo para ambos os sexos, entende-se a necessidade de realização de mais estudos focados nessa capacidade física em atividades escolares.

No que diz respeito ao escore de ATF, os dados deste estudo mostram que as aulas de EF não propiciaram mudanças significativas. Contudo, considerando que a recomendação atual para a prática de ATF na adolescência é de 300 minutos de atividades moderadas e/ ou vigorosas por semana ${ }^{5,37}$, a mediana dos resultados iniciais e finais relativos às seçôes deslocamento e lazer, se somadas ao tempo de atividades das aulas de EF, faz com que os alunos pertencentes a esta amostra atinjam os valores esperados para a adolescência.

Dados de Ribeiro ${ }^{38}$, coletados junto a adolescentes, mostraram que tanto alunos que tiveram contato apenas com preceitos teóricos acerca de formas de aumentar o nível de atividade física cotidiano, quanto alunos que tiveram contato apenas com práticas motoras, modificaram seu nível de atividade física ao longo do tempo. Contudo, poucos estudos se destinam a intervir, apesar de a escola e, por conseguinte, a EF, ser um dos espaços mais cobrados pelo estilo de vida cada vez mais sedentário de crianças e adolescentes.

Os resultados também permitem a construção da hipótese deque os alunos que não realizavam nenhuma atividade extracurricular obtiveram modificaçôes significativas em todas as capacidades físicas analisadas, bem como na avaliação do conhecimento. Os alunos que realizavam atividades extraclasse esporadicamente tiveram modificaçóes significativas na resistência abdominal e no conhecimento.

Tais achados indicam a possibilidade de a EFE, se trabalhada mediante aulas estruturadas, ser um espaço para possíveis modificações na aptidão física relacionada à saúde, a curto e longo prazo. Além disso, as modificações significativas na avaliação teórica mostram que, mais que um espaço para a realização de exercícios, as aulas de EF podem oferecer ao aluno momentos de aprendizado e reflexão sobre as questóes relativas ao exercício físico e à saúde.

Além do destaque às modificaçôes quantitativas na aptidão física e no conhecimento dos escolares intermediados por esta pesquisa, é necessário também discutir a viabilidade de propostas pedagógicas que tenham como escopo a promoção da saúde na escola. Fundamentadas por: Devide et al. ${ }^{12}$, Ferreira ${ }^{11}$, Guedes e Guedes ${ }^{39}$, Pereira ${ }^{10}$ e Nahas e Corbin ${ }^{9}$, as aulas desenvolvidas neste trabalho tiveram como preocupação central, além de aprimorar o condicionamento físico dos escolares, dar sentido às atividades praticadas nas aulas, mostrando o quanto as mesmas sáo importantes para suas vidas.

O sentido pedagógico a que se remeteu esse trabalho consistiu em oferecer aos escolares respaldos teóricos que lhes possibilitassem compreender os benefícios concedidos pela prática de exercícios físicos e entender as interferências de questôes biológicas, técno-motoras e sociopolíticas. Conforme Pereira ${ }^{10}$ é necessário unir o físico e o social por intermédio do exercício físico, tendo em vista que este é o fator que diferencia a EF das demais disciplinas na escola. Dessa forma, os escolares ao finalizar a Educação Básica, podem se tornar indivíduos fisicamente ativos e conscientes das inter-relaçôes que afetam a cultura de tempo livre.

Os resultados encontrados nesta pesquisa, e também das citadas anteriormente, mostram a possibilidade de desenvolvimento de uma EFE que tenha como foco central a promoção da saúde. Além disso, de acordo com os $\mathrm{PCNs}^{14}$, a EF pode ter impacto na educação social dos escolares, quando tem como objetivo pedagógico o exercício físico na manutenção de uma boa saúde e qualidade de vida. Contudo, é necessário que açóes pedagógicas, como as que foram desenvolvidas neste estudo, façam parte do cotidiano das aulas de EF, possibilitando a mais alunos benefícios cognitivos e motores tais como encontrados neste e em outros trabalhos.

No que diz respeito aos conteúdos de ensino desenvolvidos nessa pesquisa, deu-se ênfase à Ginástica, trabalhada mediante a metodologia denominada como GI. Esse destaque foi dado visando desenvolver um conteúdo que, ao longo dos anos, perdeu espaço nas aulas de EF, que cada vez mais têm priorizado as atividades esportivas ${ }^{16,19,22,40}$. Os achados desse estudo podem indicar que, com apropriada metodologia, é possível reativar a Ginástica como conteúdo de ensino na EF no EM. Contudo, devido às limitações a que foi submetido o mesmo, são necessários mais dados para a comprovação dessa hipótese.

Os resultados desta pesquisa reforçam a importância da Ginástica para o cotidiano da EFE. Para o desenvolvimento da Ginástica como conteúdo de ensino da EF, sem desconsiderar os outros, é necessário que a mesma seja subsidiada por procedimentos de ensino dotados de consistência metodológica. 
Além disso, também se deve fazer menção à importância da união entre teoria e prática nas aulas. A EF, espaço na escola dedicado ao aprendizado de diferentes práticas corporais, não pode oferecer aos alunos atividades desprendidas dos pressupostos teóricos. Concordando com proposições de PEReira $^{10,41}$, Guedes e Guedes ${ }^{39}$, Nahas e Corbin ${ }^{9}$ dentre outros, a EFE deve propiciar aos escolares, além de práticas motoras que estimulem o aumento da aptidão física relacionada à saúde, conhecimentos que fundamentem a aprendizagem.

A pedagogia da EF que atente aos pressupostos teóricos associados às práticas motoras poderia, sem dúvida, justificar a presença de diferentes conteúdos nas aulas de EF. Além disso, poderia motivar os escolares a exercitarem-se, com estímulos capazes de alterar sua aptidão física. Dessa forma, a EF poderia ser vista na escola como uma disciplina contextualizada e importante para a vida dos alunos, capaz de contribuir para formar cidadãos que tenham autonomia e capacidade crítica para entender o mundo que os cerca.

Desse modo, apesar de algumas limitações logísticas comuns em um trabalho de caráter interventivo desenvolvido em um espaço educacional, este estudo indicou a possibilidade de modificaçóes significativas tanto na aptidão física relacionada à saúde quanto no conhecimento em escolares do EM. O que foi encontrado aproximou-se dos resultados de outras intervenções de caráter pedagógico, levando-se em conta, obviamente, as peculiaridades de cada estudo. Entretanto, os resultados deste e de outros trabalhos podem indicar a possibilidade de a EF ter um impacto maior sobre a APF e o conhecimento no EM.

Os dados conseguidos nesta pesquisa abrem precedentes para a reflexão acerca do importante papel que a EF pode ter na formação de indivíduos ativos, conhecedores dos benefícios da exercitação física continuada e, futuramente, cidadãos que se utilizem dos conceitos adquiridos durante sua vida escolar para a obtenção de uma melhor qualidade de vida. Os resultados indicam que a EFE, trabalhada de forma estruturada no que diz respeito aos seus procedimentos de ensino e aos conteúdos, pode cumprir uma função muito mais importante na escola do que a desempenha atualmente.

As aulas deste trabalho tiveram como conteúdo de ensino primordial a Ginástica, trabalhada por meio da GI. A Ginástica é prevista em diferentes referenciais teóricos da EF como um dos conteúdos a ser desenvolvido na escola. Contudo, dados da realidade mostram que a Ginástica não vem sendo contemplada apropriadamente na EFE. Os resultados deste estudo abrem precedentes para que, assim como a Ginástica, outros conteúdos pouco trabalhados no universo da EF, como as Lutas e a Dança, por exemplo, sejam desenvolvidos no cotidiano escolar. Dessa forma, a EF atenderá a um dos pressupostos básicos da promoçáo da saúde na EF: a variabilidade de conteúdos de ensino.

Por fim, para que os efeitos positivos de uma intervenção pedagógica voltada ao estímulo e a compreensão da pratica de exercícios físicos, mostrada neste trabalho possa se tornar uma realidade mais constante, é necessário que o atual quadro da EFE se modifique drasticamente. É essencial que sejam possibilitadas aos alunos práticas pedagógicas dotadas de cientificidade, providas de comprometimento tanto por parte dos órgãos públicos quanto por parte dos docentes. É fundamental que uma EF de qualidade não seja apenas um objeto de pesquisa, e sim uma realidade no meio escolar, para que, dessa maneira, ela adquira a devida valorização na escola. Para tal, devem ser propiciados aos docentes, além de uma remuneração digna, condições materiais e instalaçóes apropriadas e tempo disponível para elaboração e desenvolvimento das aulas, avaliaçóes e suas discussóes com os alunos.

\section{Abstract}

\section{Physical education in middle school: development of concepts and health-related physical fitness}

The aim of this study was to investigate the development of concepts, levels of physical fitness related to health and physical activity patterns provided by the Physical Education (PE) classes. The sample consisted of 40 students ( 24 boys, 16 girls) high school students. Physical fitness was measured by the sit and reach test, running in 9 minutes and abdominal strength in 1 minute, belonging to the battery of tests PROESP. The knowledge was determined by theoretical test. The physical activity score was estimated by the International Physical Activity Questionnaire (IPAQ). In 30 PE classes the teaching contents 
were related to the concepts of stretching and gym exercises: Interval fitness and running. There were significant changes in abdominal strength, flexibility and knowledge to both sexes and aerobic endurance for girls, indicating that classes, worked through teaching procedures aimed at health promotion can modify the concepts and health-related physical fitness of high school students.

KeY words: Physical education; Knowledge; Physical fitness; Gym; Middle school.

\section{Referências}

1. Gordon-Larsen P, Nelson MC, Popkin BM. Longitudinal physical activity and sedentary behavior trends: adolescent to adulthood. Am J Prev Med. 2004;27:277-83.

2. Twisk JW. Physical activity guidelines for children, and adolescents: a critical review. Sports Med. 2001;31:617-27.

3. Bouchard C, Blair SN, Church TS, Earnest CP, Hagberg JM. Adverse metabolic response to regular exercise: is it a rare or common occurrence? PloS One. 2012;7: e37887.

4. Boreham C, Riddoch C. The physical activity, fitness and health of children. J Sports Sci. 2001;19:15-29.

5. Strong WB, Malina RM, Blimkie CJ, et al. Evidence based physical activity for school-age youth. J Pediatr. 2005;146:732-7.

6. Hallal PC, Bertoldi AA, Gonçalves H, Victora CG. Prevalence of sedentary lifestyle and associated factors in adolescents aged 10 to 12 years. Cad Saúde Pública. 2006;22:1277-87.

7. Hoenher CM, Soares J, Parra Perez D, et al. Physical activity interventions in Latin America: a systematic review. Am J Prev Med. 2008;34:224-33.

8. Salmon J, Both ML, Phongsavan P, Murphy N, Timperio A. Promoting physical activity participation among children and adolescents. Epidemiol Rev. 2007;29:144-59.

9. Nahas MV, Corbin CB. Aptidão física e saúde nos programas de educação física: desenvolvimentos recentes e tendências internacionais. Rev Bras Cienc Mov. 1992;6:47-58.

10. Pereira FM. O cotidiano escolar e a educação física necessária. 2a ed. Pelotas: Universitária/UFPEL; 1997.

11. Ferreira MS. Aptidão física e saúde na educação física escolar: ampliando o enfoque. Rev Bras Cienc Esporte. 2001;22:41-54.

12. Devide FP, Oliveira GAS, Ferreira MS. Ampliando o campo de intervenção da educação física escolar a partir da análise da escada da aptidão para toda a vida. Rev Pensar Prát. 2005;8:146-52.

13. Brasil. Ministério da Educaçáo e do Desporto. Secretaria de Educação Fundamental. Parâmetros curriculares nacionais: Educação Física. Brasília: Secretaria de Educação Fundamental; 1998.

14. Brasil. Ministério da Educaçáo e do Desporto. Secretaria de Educação Média e Tecnológica. Parâmetros curriculares nacionais: educação física. Brasília: Secretaria de Educação Média e Tecnológica; 1999.

15. Guedes DP. Educação para a saúde mediante programas de educação física escolar. Motriz. 1999;5:10-5.

16. Pereira FM, Silva AC. Sobre os conteúdos da educação física no ensino médio em diferentes redes educacionais do Rio Grande do Sul. Rev Educ Fís/UEM. 2004;15:68-77.

17. Pereira FM. Nível médio de ensino, educação física e conhecimento. Rev Paul Educ Fís. 2000;14:32-53.

18. Silveira EF, Silva MC. Conhecimento sobre atividade física dos estudantes de uma cidade do sul do Brasil. Motriz. 2011;17:456-67.

19. Guedes DP, Guedes JERP. Esforços físicos nos programas de educação física escolar. Rev Paul Educ Fís. 2001;15:33-44.

20. Hino AAF, Reis RS, Añez CRR. Observação dos níveis de atividade física, contexto das aulas e comportamento do professor em aulas de educação física do ensino médio da rede pública. Rev Bras Ativ Fís Saúde. 2007;12:21-30.

21. Kremer MM. Intensidade e duração dos esforços físicos em aulas de educação física curriculares [dissertação]. Pelotas: Universidade Federal de Pelotas; 2010.

22. Toledo E. Proposta de conteúdos para ginástica escolar: um paralelo com a teoria de Coll [dissertação]. Campinas (SP): Universidade Estadual de Campinas, Faculdade de Educação Física; 1999.

23. Azevedo Junior MR, Araújo CLP, Pereira FM. Atividades físicas e esportivas na adolescência: mudanças de preferências ao longo das últimas décadas. Rev Bras Educ Fís Esporte. 2006;20:51-8.

24. Richardson JR. Pesquisa social: métodos e técnicas. 3a ed. São Paulo: Atlas; 2010.

25. ABEP. Associação Brasileira de Empresas de Pesquisa. EmpreCritério de classificação econômica Brasil. São Paulo: ABEP; 2010. [citado nov. 2010]. Disponível em: http://www.abep.org/novo/Content.aspx?ContentID=301.

158 • Rev Bras Educ Fís Esporte, (São Paulo) 2014 Jan-Mar; 28(1):147-61 
26. Gaya ACA. PROESP: Projeto Esporte Brasil: manual de aplicação de medidas e testes, normas e critérios de avaliação. Porto Alegre: UFRGS; 2009.

27. Pereira FM. Ginástica intervalada: exercite-se pensando. Pelotas: Universitária/UFPEL; 2005.

28. Schuldheisz JM, Van Der Mars H. Active supervision and students physical activity in middle school physical education. J Teach Phys Educ. 2001;21:75-90.

29. Xiang P, Lee A. Achievement goals, percived motivacional climate and students sef-reported mastery behaviors. Res Q Exerc Sport. 20002;73:58-65.

30. Mosston M, Ashworth S. The spectrum of teaching styles: from command to discovery. New York: Longman; 1990.

31. Pereira FM. Procedimentos de ensino de conteúdos cognitivos em aulas de educação física escolar. Rev Biomotriz. 2011;5:17-25.

32. Anderson B. Alongue-se. São Paulo: Summus; 1983.

33. Powers SK, Howley ED. Fisiologia do exercício: teoria e aplicação ao condicionamento e ao desempenho. 5a ed. Barueri: Manole; 2005.

34. Milanezi JZ. Atividade Física para saúde no ensino médio e no tempo livre: estudo quase-experimental em Bauru - SP [dissertação]. Campinas (SP): Universidade Estadual de Campinas, Faculdade de Educação Física; 2001.

35. Shonardie Filho L. Educação física na primeira série do ensino médio: uma prática por compromisso [dissertação]. Campinas (SP): Universidade Estadual de Campinas, Faculdade de Educação Física; 2001.

36. Pereira FM. A favor da ginástica no cotidiano da educação física no ensino médio. Rev Bras Ativ Fís Saúde. 2006;11:47-58.

37. Pate RR, Freedson PS, Sallis JF, et al. Compliance with physical activity guidelines: prevalence in a population of children and youth. Ann Epidemiol. 2002;12:303-8.

38. Ribeiro EHC. Efeito de dois programas de intervenção no nível de atividade física de adolescentes matriculados em escolas da rede pública da zona leste da cidade de São Paulo - SP [dissertação]. São Paulo (SP): Universidade de São Paulo, Faculdade de Saúde Pública; 2009.

39. Guedes DP, Guedes JERP. Educação física escolar: uma proposta de promoção da saúde. Rev Assoc Prof Educ Fís Londrina. 1993;14:16-23.

40. Rinaldi IEB, Souza EPM. A ginástica no percurso escolar dos ingressantes dos cursos de licenciatura em educação física da Universidade Estadual de Maringá e da Universidade Estadual de Campinas. Rev Bras Ciênc Esporte. 2003;24:159-73.

41. Pereira FM Dialética da cultura física: introdução à crítica da educação física, do esporte e da recreação. São Paulo: Ícone; 1988.

ANExo 1 - Prova teórica para coleta de dados.

Questáo 1: Dentre as patologias (doenças) listadas abaixo, marque a alternativa que não é consequência da manutenção de hábitos de vida sedentários $(1,0)$ :

( ) Infarto do miocárdio

( ) Hipertensão

( ) Osteoporose

( ) Câncer de pele

( ) Diabetes tipo II

Questấo 2: O seguinte texto: "É dever do Estado fomentar práticas desportivas formais e não-formais, como direito de cada um ..." encontra-se na $(o)(1,0)$ :

( ) Esse texto inexiste

( ) Constituição Federal Brasileira

( ) Regimento do Comitê Olímpico brasileiro

( ) Parecer número 01 do Conselho Federal de Educação Física

( ) Estatuto da Confederaçáo Brasileira de Desporto 
Questão 3: Sabendo que os alimentos fonte de carboidratos (CHO) (arroz, pão, massa, frutas), de gordura (LIP) (óleos, margarinas,) e de proteinas (PRO) (carnes, ovos, laticínios) são fonte de energia para a realização das funçōes orgânicas vitais, qual a proporção dos macronutrientes citados que é correta para a obtenção de uma alimentação diária equilibrada?

( ) $\mathrm{CHO}>\mathrm{PRO}>\mathrm{LIP}$

( ) $\mathrm{PRO}>\mathrm{CHO}>\mathrm{LIP}$

( ) $\mathrm{CHO}>\mathrm{LIP}>\mathrm{PRO}$

( ) $\mathrm{LIP}>\mathrm{CHO}>\mathrm{PRO}$

( ) $\mathrm{PRO}>\mathrm{LIP}>\mathrm{CHO}$

Questão 4: Dentre as formas de exercitação listadas abaixo, qual delas caracteriza um exercício aeróbico $(1,0)$ :

( ) Praticar Yoga durante 50 minutos

( ) Fazer musculação durante 60 minutos

( ) Jogar na posição de goleiro de futsal durante 40 minutos

( ) Realizar exercícios de alongamento durante 20 minutos

( ) Andar de bicicleta continuamente durante 60 minutos

Questáo 5: Dentre as patologias (doenças) citadas abaixo, qual delas tem como principal fator preventivo a prática de exercícios de força $(1,0)$ :

( ) Câncer de pulmão

( ) Pneumonia

( ) Osteoporose

( ) Hipertensão

( ) Diabetes tipo I

Questáo 6: Marque a alternativa que corresponde a um exercício de flexibilidade, para a regiäo dorso-lombar e posterior das coxas e pernas (1,0): rever o enunciado

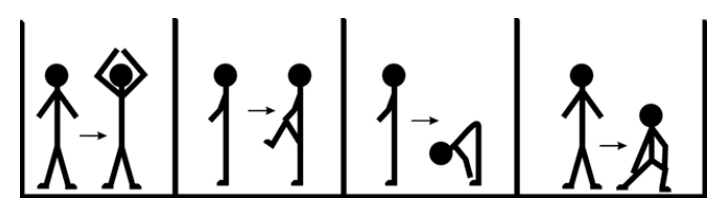

( )

( )

( )

( )

Questáo 7: Durante uma corrida a pé de 10/15 minutos (corrida aeróbica), a respiração mais indicada é: (1,0)

( ) Inspiração e expiração só pela boca.

( ) Inspiração e expiração só pelo nariz.

( ) Inspiração e expiração normal pela boca e nariz.

( ) Inspiração pelo nariz com o abdome contraído.

( ) Inspiração e expiração pelo nariz com o abdome contraído

Questão 8: À medida que aumentamos nosso condicionamento físico a partir de exercícios aeróbicos, a frequência cardíaca de repouso (quando estamos parados): $(1,0)$

( ) Aumenta em relação ao inicio do programa do exercício

( ) Diminui em relação ao inicio do programa de exercício

( ) Não se modifica

( ) Se modifica negativamente

( ) Nenhuma das anteriores está correta

160 • Rev Bras Educ Fís Esporte, (São Paulo) 2014 Jan-Mar; 28(1):147-61 
Questáo 9: Identifique, da forma mais completa possivel, a(s) musculatura(s) responsável(is) pelo movimento nos seguintes exercícios: $(2,0)$

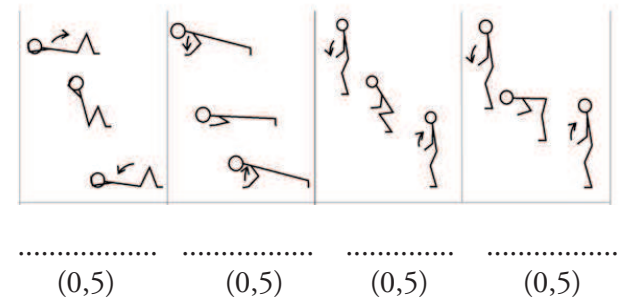

ENDEREÇO

Marcel Anghinoni Cardoso Escola Superior de Educação Física Universidade Federal de Pelotas R. Afonso Pena, 355 96040-60o - Pelotas - RS - BRASIL e-mail: mcanghinoni@yahoo.com.br
Recebido para publicação: 22/03/2012

1a. Revisão: 06/03/2013

2a. Revisão: 03/08/2013

3a. Revisão: 27/09/2013

Aceito: 30/01/2014 